\title{
Reduction of the Greenhouse Gasses Emissions in Refrigeration
}

\author{
Adriana Greco ${ }^{1 *}$, Claudia Masselli ${ }^{2}$ \\ ${ }^{1}$ Department of Industrial Engineering, University of Naples Federico II, P.le Tecchio 80, Naples 80125, Italy \\ ${ }^{2}$ Department of Industrial Engineering, University of Salerno, Via Giovanni Paolo II 132, Fisciano (SA), Italy
}

Corresponding Author Email: adriana.greco@unina.it

https://doi.org/10.18280/ti-ijes.640107

Received: 2 December 2019

Accepted: 17 February 2020

\author{
Keywords: \\ refrigerants, vapor compression, \\ greenhouse effect, GWP, ODP, HFC, HFO, \\ emissions, global warming
}

\begin{abstract}
This paper aims to draw a general framework on the reduction of the greenhouse gasses emissions in refrigeration. In this paper, the historical evolution of the refrigerants empoyed in the vapor compression-based systems with particular reference to the problems emerged in the passage from one generation of fluids to the next. Nowadays it is necessary to find valid alternatives to HydroFluoroCarbons (HFCs) due of a significant global warming potential. Among the main possible substitutes there are the low GWP drop-in refrigerants belonging to the HydroFluoroOlefins (HFOs) or the natural fluids.
\end{abstract}

\section{INTRODUCTION}

Nowadays refrigeration and air conditioning are responsible for about $20 \%$ of the worldwide energy consumption. For this, the most responsible technology is Vapor Compression (VC) since most of the refrigeration and air conditioning systems base on it. Over the years, many categories of refrigerants have been employed in vapor compression refrigeration: from CFCs and HCFCs, whose use was then banned due to their potential in destroying the stratospheric ozone; up to HFCs, that are not harmful toward ozone but due of a high Global Warming Potential (GWP). Unfortunately, HFC emissions are constantly growing (8-9\% per year). The Montreal [1] and Kyoto [2] Protocols, the subsequent amendments [3] and the consequent international and national laws and regulations deriving from them [4], established very stringent objectives aimed at a progressive reduction of the emissions of greenhouse gases and in particular at the gradual ban of HFCs, precisely because of their significant contribution to the greenhouse effect on our planet. Therefore, never as in this period it is necessary to find immediate solutions to supply in terms of eco-compatible refrigerants that can replace those now banned. This article provides a detailed overview of the refrigerants that currently constitute a more eco-compatible alternative solution for refrigeration, heat pumps and air conditioning systems.

\section{HISTORICAL EVOLUTION OF REFRIGERANTS}

From the mid-nineteenth century the first refrigerating fluids to be used were natural fluids such as: carbon dioxide, ammonia and sulfur dioxide. Because of their dangerous use and toxicity, natural fluids were replaced by synthetic fluids during the 1930s.

The initial synthetic fluids to be available as vapor compression refrigerants were the CFCs and subsequently the HCFCs. Chlorine and fluorine contained in these chemical compounds ensured good thermodynamic properties in order to guarantee safety to people during their use. In 1974 two American scientists, Rowland and Molina, discovered that the chlorine contained in these compounds was causing the thinning of the ozone layer in the stratosphere. This discovery, corroborated also by other scientific studies, led many states to stipulate agreements and protocols aimed at to take countermeasures toward the phenomenon of ozone depletion, through the progressive replacement of CFC and HCFC fluids with other less harmful fluids. The first important international agreement was the Montreal Protocol, signed on September 16, 1987. To date, 192 nations joined this agreement. Following the prescription of the Montreal Protocol, pure or mixed HFC fluids not dangerous for the ozone were introduced. Indeed, with the introduction of HFC fluids, chlorine has been completely eliminated and replaced by hydrogen, solving the problem of stratospheric ozone depletion. However, a new environmental problem has arisen: the increase temperature of our planet caused by human activities and, in part, by this new generation of refrigerant fluids. The Kyoto Protocol, drafted in 1997 and with more than 180 countries adhering, classifies HFC refrigerants as substances responsible for the direct greenhouse effect [5].

The aforementioned restrictions are forcing the transition toward a fourth generation of refrigerants with ODP and GWP satisfying the regulations. In this new generation of refrigerants there are HydroFluoroOlefins (HFO) which derive from olefins rather than from alkanes. Two known and promising HFOs are: HFO1234yf and HFO1234ze [6]. These refrigerants have zero ODP and very small GWP which guarantee a very short lifetime once released in the atmosphere $[7,8]$. The current state of the art reveals that the HFOs have been tested as drop-in replacement of domestic refrigerators previously operating with HFC134a [9-13].

Furthermore, in some fields, such as domestic refrigeration, isobutane (R600a) has already been proposed to replace HFC134a [14, 15]. However, although this solution has already been accepted by the European market, it involves some technical difficulties linked to the high flammability of the R600a. While the small amount of charge present in a 
domestic refrigerator for the European market is not of particular concern, domestic refrigerator manufacturers have had to redesign some areas of their production plant (e.g. refrigerant storage and charging stations), with consequent huge investments by the companies involved. No less important is the adoption of specific components (i.e. compressors) able to work with HydroCarbons (HC). Furthermore, as evidenced by Bansal et al. [16] the use of R600a may have high barriers to the American market (US market) due to stricter fire prevention standards (UL 250 standard), as well as other markets may be reluctant to such a solution [17].

Figure 1 shows a block diagram that describes the historical evolution of refrigerant fluids.

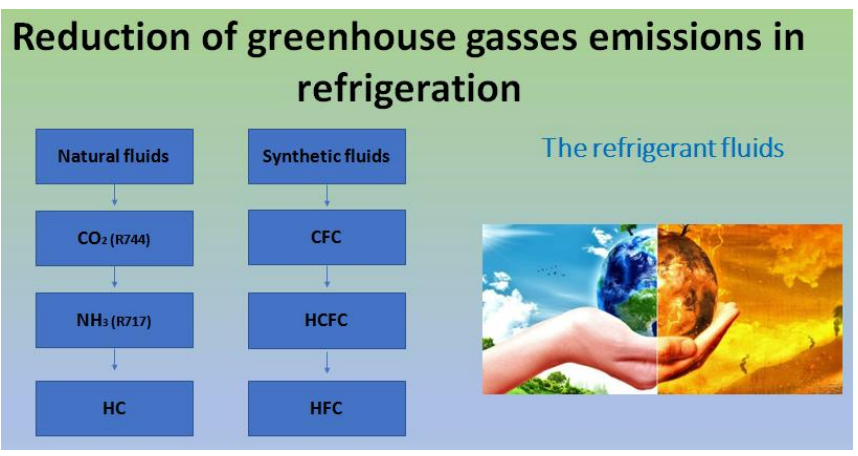

Figure 1. Historical evolution of refrigerant fluids

\section{CHARACTERISTICS AND CLASSIFICATION OF REFRIGERANT FLUIDS}

\subsection{Requirements}

A refrigerant fluid is a fluid operating in a refrigeration cycle with the purpose of subtracting heat from a cold source and releasing it in a hot on.

The main requirements that a refrigerant must have are: good thermodynamic properties, safety during use, economy and environmental compatibility.

Good thermodynamic properties are:

- $\quad$ high density, both in the gaseous and liquid state;

- $\quad$ high enthalpy of evaporation;

- boiling temperature higher than the triple point temperature and condensation temperature lower than the critical temperature;

- $\quad$ high thermal conductivity;

- chemical stability.

- $\quad$ high COP, i.e. the ratio between the amount of heat Q removed from the cold source and the work employed to remove this heat. It essentially indicates the efficiency of the refrigeration system.

Furthermore, a refrigerant fluid should have a high chemical inertia with respect to the metals, the gaskets and the lubrication oil of the compressors of the plant. In other words, the fluid must not mix with oils that could alter its chemical composition. Moreover, it must not react with the metal components used, causing corrosion. In addition to possessing good thermodynamic properties, fluids must not be dangerous to the people who use them, i.e. they must not be flammable or toxic. No less important is the impact that these fluids cause to the environment during all the various phases of their operational life cycle. The damage to the environment can derive both from the leakage of the lubricating oils and the primary fluid during the assembly and the operation of the plant, and from the indirect production of carbon dioxide during the regular system operation. Currently there is no refrigerant that satisfies all these characteristics; therefore, the choice of the refrigerant must be the result of a compromise designed to exploit its qualities to the best and to mitigate the defects.

\subsection{Classification}

All the refrigerant fluids are classified according to the internationally recognized ANSI / ASHRAE nomenclature.

Each fluid is indicated with an alphanumeric abbreviation of the type: "R - i - ii - iii - iv - v - vi".

The letter " $\mathrm{R}$ " in the prefix stands for refrigerant. It can be replaced by an abbreviation that identifies the type of refrigerant (CFC, HCFC, HCF etc.). Each number or letter in the positions following the prefix specifies the characteristics of the fluid:

- in position "i" a $\mathrm{C}$ is placed in the case of cyclic derivatives, otherwise it is omitted;

- $\quad$ in position "ii" the number of double carbon bonds is indicated, if absent, it is omitted;

- - "iii" indicates the number of carbon atoms decreased by one unit;

- $\quad$ "iv" indicates the number of hydrogen atoms of the compound increased by one unit;

- $\quad$ "v" indicates the number of fluorine atoms;

- the "vi" position can be occupied by one or more letters of the lower or upper case alphabet.

This choice is necessary since there are compounds having the same chemical composition but different arrangement of atoms (isomers). Normally an "a" is placed to denote an asymmetric positional isomer. An example, as shown in Figure 2, is given by R134a, a fluid used as a refrigerant in automotive air conditioning plants. The chlorine atoms in the compound are obtained indirectly, considering that each carbon atom must necessarily be linked to four other atoms; if the number of fluorine and hydrogen atoms is insufficient to complete the carbon bonds, a complementary number of chlorine atoms is added. Organic compounds such as hydrocarbons are classified with a number of the order of 600 . In this group the refrigerant is classified by adding the number of carbon atoms minus four presents in the compound after 6 of the series.
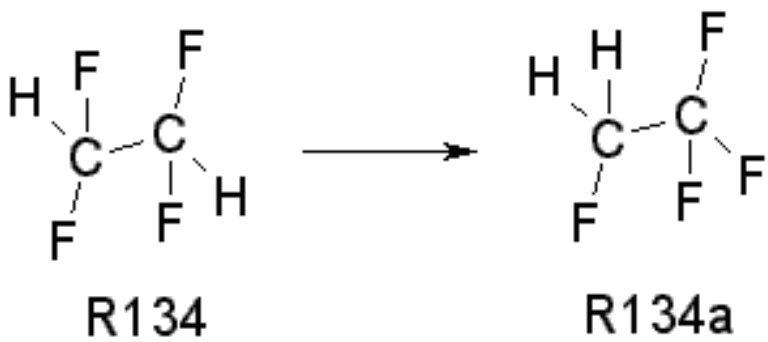

R134a

Figure 2. R134-R134a chemical structure

The refrigerants not derived from hydrocarbons, and therefore natural fluids, are grouped in the R700 series where the last two digits indicate the molecular weight of the refrigerant. For example, R717 indicates ammonia having a molecular weight of $17 \mathrm{~g} / \mathrm{mol}$. 


\subsection{Toxicity and flammability}

Regarding toxicity and flammability, reference is always made to the ANSI / ASHRAE classification.

Toxicity means: "the ability of a refrigerant to be harmful or lethal due to acute or chronic exposure by contact, inhalation or ingestion" and is indicated by a letter (A or B). The letter A indicates the refrigerants for which no toxicity was detected at concentrations less than or equal to $400 \mathrm{ppm}$; the letter B indicates the refrigerants for which there is evidence of toxicity at concentrations lower than $400 \mathrm{ppm}$.

Flammability means the minimum concentration of a substance, a refrigerant capable of propagating a flame through a homogeneous mixture of substance and air under the specified test conditions. Each fluid belongs to a flammability class $(1,2,3)$ :

- Class 1: non-flammable refrigerants, which do not propagate the flame at atmospheric pressure and at temperature $\mathrm{T}=21^{\circ} \mathrm{C}$, belong to it.

- Class 2: flammable refrigerants, which have a lower flammability limit greater than $0.10 \mathrm{~kg} / \mathrm{m}^{3}$ at $21^{\circ} \mathrm{C}$ at atmospheric pressure, and a combustion heat of less than $19 \mathrm{~kJ} / \mathrm{kg}$, belong to it.

- Class 3: this includes highly flammable refrigerants that have a lower flammability limit less than or equal to $0.10 \mathrm{~kg} / \mathrm{m}^{3}$ at a temperature of $21^{\circ} \mathrm{C}$ at atmospheric pressure, and a combustion heat of less than $19 \mathrm{~kJ} / \mathrm{kg}$.

Finally, there is an intermediate flammability class identified by the initials $2 \mathrm{~L}$ which indicates a greater flammability compared to class 1 and lower compared to class 2. Therefore, a fluid belonging to the category "B2" indicates a highly toxic fluid with a medium-low flammability. Figure 3 shows all the various combinations.

\begin{tabular}{|l|cc|}
\hline & \multicolumn{3}{|c|}{ Gruppi di sicurezza } \\
\hline Infiammabilità maggiore & A3 & B3 \\
\hline Infiammabilità & A2 & B2 \\
\hline Infiammabilità minore & A2L & B2L \\
\hline Non infiammabiltà & A1 & B1 \\
\hline & Minore tossicità & Maggiore tossicità \\
\hline
\end{tabular}

Figure 3. Refrigerant safety groups

\section{TYPES OF FLUIDS}

The refrigerants currently on the market are divided into two main categories: natural fluids and synthetic fluids.

\subsection{Natural fluids}

The term natural refrigerants mean all those substances or compounds that can be found directly in nature or whose composition does not occur by chemical synthesis. They are substances that have a low environmental impact by not containing chlorine or fluorine. Ammonia, carbon dioxide, hydrocarbons and water are natural refrigerants.

\subsubsection{Ammonia}

Ammonia was one of the first fluids to be used as a refrigerant. In $1854 \mathrm{~F}$. Carrè built a water-ammonia absorption refrigerator while in 1876 Boyle developed an ammonia compressor.

Ammonia, whose chemical formula is NH3 while the abbreviation ASHRAE is R717, is a colorless gas with a pungent smell. The thermodynamic properties of ammonia are:

- high energy efficiency, both in high and low temperature applications;

- operating pressures comparable to those of other common refrigerants;

- the possibility of using a lower refrigerant charge than the average, thanks to the high latent heat of evaporation that it possesses.

Ammonia is also inexpensive, widely available on the market and, in terms of global overheating and stratospheric ozone damage, has no environmental impact. The disadvantages that have limited its use are toxicity and flammability; in fact, ammonia belongs to the B2 safety group. Furthermore, it is corrosive towards certain alloys and some metals. It has only spread in the industrial sector as a refrigerant fluid for cooling, freezing and deep-freezing plants, whereas in the commercial sector it has always been replaced by HFCs. Some important technical advances have allowed ammonia to spread to other fields besides the industrial one. These advances include:

- the development of some hermetic components of the refrigeration system such as the compressor;

- the use of alloys compatible with the fluid;

- the use of new soluble lubricants in the fluid.

These technical interventions have led to higher plant production costs that are not always sustainable for smaller capacity systems developing.

\subsubsection{Carbon dioxide}

The first uses of $\mathrm{CO}_{2}$ as a refrigerant date back to almost 150 years ago. In 1866 Thaddeus Lowe was able to adapt a compressor used for ice production to $\mathrm{CO}_{2}$. Carbon dioxide is a colorless and odorless gas. The thermophysical properties of $\mathrm{CO}_{2}$ are:

- $\quad$ very small kinematic viscosity;

- large density;

- high working pressures that require specific plant interventions;

- inertia at ordinary temperatures and compatible with all the most common materials, although in the wet state it is corrosive towards almost all metals except stainless steels;

- low critical temperature $\left(30^{\circ} \mathrm{C}\right)$ such as to make the thermal gradient between the cold source and the hot source too limited, with a consequent small quantity of heat exchanged.

It is easily available in the environment and is often the waste product of technological processes, so its cost is very low. Carbon dioxide is not very polluting and is used as a reference gas to quantify the impact of other refrigerant gases on the environment. It is non-flammable, chemically stable and not dangerous in water. However, although it is not toxic, if present in a considerable quantity in an enclosed space it can lead to asphyxia. Compared to other refrigerants, the $\mathrm{CO}_{2}$ system efficiency is more influenced by the type of application and the climate. In fact, with the increase in temperature the efficiency of a system that uses carbon dioxide decreases. This is an important aspect because it constitutes a strong limitation to the use of $\mathrm{CO}_{2}$ in countries characterized by warm climate.

\subsubsection{Hydrocarbons}

Hydrocarbons are organic compounds, mainly of fossil origin, composed only of carbon and hydrogen atoms. They 
have good thermodynamic properties, including a high heat transport that allows a lower refrigerant charge. In terms of efficiency, they are able to compete with HFCs and HCFCs, reaching high COP values in most applications. Among the advantages of hydrocarbons there is compatibility with many lubricants used in the equipment with the exception of those containing silicone and silicates. They are also used in mixtures (together, for example, with HFCs), allowing an easier retrofit operation of plants loaded with CFCs. They have a low environmental impact, are not toxic but are highly flammable belonging to the A3 safety class. For this reason, they have limitations on use in terms of the quantities allowed in the equipment. Hydrocarbons such as propane and isobutane find application in the refrigeration sector, while other hydrocarbons are used as alternative foaming agents in the production of foams.

\subsubsection{Water}

The water is odorless, colorless, has no environmental impact and is the most economical natural refrigerant. It has high values of latent heat of evaporation and of critical temperature so it can be used even in very hot climates. It is not toxic, flammable or explosive, therefore it represents, from this point of view, a valid solution. It has the following characteristics that limit its use as a primary refrigerant:

- low solidification temperature at atmospheric pressure;

- over time it causes corrosion and oxidation in metals;

- high specific volume value that makes the compression process at low pressures in vapor compression refrigeration cycles challenging.

From a plant engineering point of view, interventions such as the use of large compressors and the use of titanium alloys are necessary. It is a substance still under study. Table 1 below summarizes the main aspects of natural fluids.

Table 1. Properties of natural fluids

\begin{tabular}{cccc}
\hline $\begin{array}{c}\text { Type of } \\
\text { Fluid }\end{array}$ & $\begin{array}{c}\text { Environmental } \\
\text { Impact }\end{array}$ & $\begin{array}{c}\text { Safety } \\
\text { class }\end{array}$ & Performances \\
\hline Ammonia & Zero & B2 & Good \\
\hline $\begin{array}{c}\text { Carbone } \\
\text { dioxide }\end{array}$ & Low & A1 & Medium-low \\
\hline Hydrocarbons & Low & A3 & High \\
\hline Water & Zero & A1 & Medium-low \\
\hline
\end{tabular}

\subsection{Synthetic fluids}

The synthetic refrigerating fluids which have been used most often belong to the family of alkyl halides. Based on the presence or absence of chlorine in the compound, these fluids can be divided into three large groups: CFC, HCFC, HCF.

\subsubsection{CFC}

Chlorine-fluoro-carbides are synthesis products deriving from the first hydrocarbons of the saturated paraffin series, methane $\left(\mathrm{CH}_{4}\right)$ and ethane $\left(\mathrm{C}_{2} \mathrm{H}_{6}\right)$, by replacing all the hydrogen atoms in the molecule with chlorine $(\mathrm{Cl})$ and fluorine atoms $(\mathrm{F})$.

This compound was first synthesized by Thomas Midgley, who announced its invention in April 1930 and from 1931 was commercially available. At first they were used only as refrigerant fluids, but over the years they became widespread in various sectors becoming central in the production, for example, of detergents in the electronics industry, of foaming agents in plastic foams, of solvents in the chemical industry, of tracer fluids and chemical products to extinguish fires. The replacement of a hydrogen atom with a fluorine one causes an increase in density while the substitution of a hydrogen atom with one of chlorine generally causes an increase in the latent heat of evaporation and a reduction in the boiling temperature. CFCs are low boiling: they boil at atmospheric pressure and at temperatures lower than room temperature range. They are colorless, odorless or with a faint odor of ether. All CFCs have the following important properties:

- not flammable;

- not toxic for humans;

- chemically stable;

- guarantee good performances of the refrigeration systems in relation to their charge;

- production costs are relatively low.

Although CFCs possess good properties, the characteristics that have determined their success in various sectors are nontoxicity and non-flammability. The great chemical stability, which represents an advantage during use, has proved over time to be the most important disadvantage from the environmental point of view given their high potential for destruction of the stratospheric ozone (ODP).

Some important CFCs are shown in Table 2.

Table 2. CFC refrigerants

\begin{tabular}{cc}
\hline Abbreviation & Chemical formula \\
\hline $\mathrm{R} 10$ & $\mathrm{CCl}_{4}$ \\
\hline $\mathrm{R} 11$ & $\mathrm{CFCl}_{3}$ \\
\hline $\mathrm{R} 12$ & $\mathrm{CF}_{2} \mathrm{Cl}_{2}$ \\
\hline $\mathrm{R} 13$ & $\mathrm{CF}_{3} \mathrm{Cl}$ \\
\hline $\mathrm{R} 111$ & $\mathrm{C}_{2} \mathrm{FCl}_{5}$ \\
\hline $\mathrm{R} 112$ & $\mathrm{C}_{2} \mathrm{~F}_{2} \mathrm{Cl}_{4}$ \\
\hline $\mathrm{R} 113$ & $\mathrm{C}_{2} \mathrm{~F}_{3} \mathrm{Cl}_{3}$ \\
\hline $\mathrm{R} 114$ & $\mathrm{C}_{2} \mathrm{~F}_{4} \mathrm{Cl}_{2}$ \\
\hline $\mathrm{R} 115$ & $\mathrm{C}_{2} \mathrm{~F}_{5} \mathrm{Cl}$ \\
\hline $\mathrm{R} 211$ & $\mathrm{C}_{3} \mathrm{~F}_{2} \mathrm{Cl}_{7}$ \\
\hline $\mathrm{R} 212$ & $\mathrm{C}_{3} \mathrm{~F}_{2} \mathrm{Cl}_{6}$ \\
\hline $\mathrm{R} 213$ & $\mathrm{C}_{3} \mathrm{~F}_{3} \mathrm{Cl}_{5}$ \\
\hline $\mathrm{R} 214$ & $\mathrm{C}_{3} \mathrm{~F}_{4} \mathrm{Cl}_{4}$ \\
\hline $\mathrm{R} 215$ & $\mathrm{C}_{3} \mathrm{~F}_{5} \mathrm{Cl}_{3}$ \\
\hline $\mathrm{R} 216$ & $\mathrm{C}_{3} \mathrm{~F}_{6} \mathrm{Cl}_{2}$ \\
\hline $\mathrm{R} 217$ & $\mathrm{C}_{3} \mathrm{~F}_{7} \mathrm{Cl}$ \\
\hline &
\end{tabular}

\subsubsection{HCFC}

HCFCs characterize the second generation of synthetic fluids and also belong to the family of alkyl halides. From the point of view of the chemical composition they are distinguished from the CFCs for having replaced a part of chlorine in the compound with hydrogen. This substitution has two direct consequences:

- greater instability once dispersed in the atmosphere, where it tends to decompose more rapidly than CFCs;

- moderate flammability and toxicity increases compared to CFCs.

Furthermore, this replacement does not affect the chemical and physical stability of the refrigerant, preventing the formation of substances or new compounds when it is inside a refrigeration circuit. They are generally also colorless and odorless. Since the fields of application of HCFCs have been conceived as CFC substitutes, they are the same.

Some important HCFCs are reported in Table 3. The R22, present in this list, is the most used refrigerant fluid in the field 
of commercial and industrial air conditioning $[18,19]$. It has a refrigerating effect equal to that of ammonia with the difference that it has more reduced compression ratios

Table 3. HCFC refrigerants

\begin{tabular}{cccc}
\hline Abbreviation & $\begin{array}{c}\text { Chemical } \\
\text { formula }\end{array}$ & Abbreviation & $\begin{array}{c}\text { Chemical } \\
\text { formula }\end{array}$ \\
\hline $\mathrm{R} 21$ & $\mathrm{CHFCl} 2$ & $\mathrm{R} 225$ & $\mathrm{C}_{3} \mathrm{HF}_{5} \mathrm{Cl}_{2}$ \\
\hline $\mathrm{R} 22$ & $\mathrm{CHF}_{2} \mathrm{Cl}$ & $\mathrm{R} 226$ & $\mathrm{C}_{3} \mathrm{HF}_{6} \mathrm{Cl}$ \\
\hline $\mathrm{R} 31$ & $\mathrm{CH}_{2} \mathrm{FCl}$ & $\mathrm{R} 231$ & $\mathrm{C}_{3} \mathrm{H}_{2} \mathrm{FCl}_{5}$ \\
\hline $\mathrm{R} 121$ & $\mathrm{C}_{2} \mathrm{HFCl}_{4}$ & $\mathrm{R} 232$ & $\mathrm{C}_{3} \mathrm{H}_{2} \mathrm{~F}_{2} \mathrm{Cl}_{4}$ \\
\hline $\mathrm{R} 122$ & $\mathrm{C}_{2} \mathrm{HF}_{2} \mathrm{Cl}_{3}$ & $\mathrm{R} 233$ & $\mathrm{C}_{3} \mathrm{H}_{2} \mathrm{~F}_{3} \mathrm{Cl}_{3}$ \\
\hline $\mathrm{R} 123$ & $\mathrm{C}_{2} \mathrm{HF}_{3} \mathrm{Cl}_{2}$ & $\mathrm{R} 234$ & $\mathrm{C}_{3} \mathrm{H}_{3} \mathrm{~F}_{4} \mathrm{Cl}_{2}$ \\
\hline $\mathrm{R} 124$ & $\mathrm{C}_{2} \mathrm{HF}_{4} \mathrm{Cl}$ & $\mathrm{R} 235$ & $\mathrm{C}_{3} \mathrm{H}_{2} \mathrm{~F}_{5} \mathrm{Cl}$ \\
\hline $\mathrm{R} 131$ & $\mathrm{C}_{2} \mathrm{H}_{2} \mathrm{FCl}_{3}$ & $\mathrm{R} 241$ & $\mathrm{C}_{3} \mathrm{H}_{3} \mathrm{FCl}_{4}$ \\
\hline $\mathrm{R} 132$ & $\mathrm{C}_{2} \mathrm{H}_{2} \mathrm{~F}_{2} \mathrm{Cl}_{2}$ & $\mathrm{R} 242$ & $\mathrm{C}_{3} \mathrm{H}_{3} \mathrm{~F}_{2} \mathrm{Cl}_{3}$ \\
\hline $\mathrm{R} 133$ & $\mathrm{C}_{2} \mathrm{H}_{2} \mathrm{~F}_{3} \mathrm{Cl}$ & $\mathrm{R} 243$ & $\mathrm{C}_{3} \mathrm{H}_{3} \mathrm{~F}_{3} \mathrm{Cl}_{2}$ \\
\hline $\mathrm{R} 141$ & $\mathrm{C}_{2} \mathrm{H}_{3} \mathrm{FCl}_{2}$ & $\mathrm{R} 244$ & $\mathrm{C}_{3} \mathrm{H}_{3} \mathrm{~F}_{4} \mathrm{Cl}$ \\
\hline $\mathrm{R} 142$ & $\mathrm{C}_{2} \mathrm{H}_{3} \mathrm{~F}_{2} \mathrm{Cl}$ & $\mathrm{R} 251$ & $\mathrm{C}_{3} \mathrm{H}_{4} \mathrm{FCl}_{3}$ \\
\hline $\mathrm{R} 151$ & $\mathrm{C}_{2} \mathrm{H}_{4} \mathrm{FCl}_{2}$ & $\mathrm{R} 252$ & $\mathrm{C}_{3} \mathrm{H}_{4} \mathrm{~F}_{2} \mathrm{Cl}_{2}$ \\
\hline $\mathrm{R} 221$ & $\mathrm{C}_{3} \mathrm{HFCl}_{6}$ & $\mathrm{R} 253$ & $\mathrm{C}_{3} \mathrm{H}_{4} \mathrm{~F}_{3} \mathrm{Cl}$ \\
\hline $\mathrm{R} 222$ & $\mathrm{C}_{3} \mathrm{HF}_{3} \mathrm{Cl}_{5}$ & $\mathrm{R} 261$ & $\mathrm{C}_{3} \mathrm{H}_{5} \mathrm{FCl}_{2}$ \\
\hline $\mathrm{R} 223$ & $\mathrm{C}_{3} \mathrm{HF}_{3} \mathrm{Cl}_{4}$ & $\mathrm{R} 262$ & $\mathrm{C}_{3} \mathrm{H}_{5} \mathrm{~F}_{2} \mathrm{Cl}$ \\
\hline $\mathrm{R} 224$ & $\mathrm{C}_{3} \mathrm{HF}_{4} \mathrm{Cl}_{3}$ & $\mathrm{R} 271$ & $\mathrm{C}_{3} \mathrm{H}_{6} \mathrm{FCl}$ \\
\hline & & &
\end{tabular}

\subsubsection{HFC}

Introduced as a substitute for CFCs and then HCFCs from the early 1990s, HFCs are the third generation of refrigerants. They are compounds formed by hydrogen, fluorine and carbon atoms. They are average non-flammable, with low toxicity and good energy efficiency [20]. They are colorless, odorless and non-aggressive with respect to materials such as copper and plastic and non-reactive. The success of this type of refrigerants has not been exciting, especially with regards to its use as pure fluids. The cause must be attributed to the fact that HFC fluids do not in most cases offer comparable performance with CFC and HCFC refrigerants, so that the retrofitting of old systems is not always simple and possible. Currently HFCs are used more as components for mixtures. With these, it is possible to calibrate the thermodynamic characteristics of the refrigerant that must go to replace the CFCs and HCFCs in existing plants. The absence of chlorine in the compound guarantees HFCs a zero impact on the environment from the point of view of stratospheric ozone destruction, unlike CFCs and HCFCs; however, HFCs are harmful from the point of view of global warming potential and therefore of the greenhouse effect. Some HFCs are shown in Table 4.

Table 4. HFC refrigerants

\begin{tabular}{ccc}
\hline Abbreviation & Chemical formula & GWP \\
\hline HFC23 & $\mathrm{CHF}_{3}$ & 14800 \\
\hline HFC32 & $\mathrm{CH}_{2} \mathrm{~F}_{2}$ & 675 \\
\hline HFC41 & $\mathrm{CH}_{3} \mathrm{~F}$ & 92 \\
\hline HFC125 & $\mathrm{CHF}_{2} \mathrm{CF}_{3}$ & 3500 \\
\hline HFC-125a & $\mathrm{CH}_{3} \mathrm{CHF}_{2}$ & 124 \\
\hline HFC134 & $\mathrm{CHF}_{2} \mathrm{CHF}_{2}$ & 1100 \\
\hline HFC134a & $\mathrm{CH}_{2} \mathrm{FCF}_{3}$ & 1430 \\
\hline HFC143 & $\mathrm{CHF}_{2} \mathrm{CH}_{2} \mathrm{~F}$ & 353 \\
\hline HFC143a & $\mathrm{CH}_{3} \mathrm{CF}_{3}$ & 4470 \\
\hline HFC152 & $\mathrm{CH}_{2} \mathrm{FCH}_{2} \mathrm{~F}$ & 53 \\
\hline HFC-161 & $\mathrm{CH}_{3} \mathrm{CH}_{2} \mathrm{~F}$ & 12 \\
\hline HFC-227ea & $\mathrm{CF}_{3} \mathrm{CHFCF}_{3}$ & 3220 \\
\hline
\end{tabular}

\begin{tabular}{ccc}
\hline HFC-236cb & $\mathrm{CH}_{2} \mathrm{FCF}_{2} \mathrm{CF}_{3}$ & 1340 \\
\hline HFC-236ea & $\mathrm{CHF}_{2} \mathrm{CHFCF}_{3}$ & 1370 \\
\hline HFC-236fa & $\mathrm{CF}_{3} \mathrm{CH}_{2} \mathrm{CF}_{3}$ & 9810 \\
\hline HFC-245ca & $\mathrm{CH}_{2} \mathrm{FCF}_{2} \mathrm{CHF}_{2}$ & 693 \\
\hline HFC-245fa & $\mathrm{CHF}_{2} \mathrm{CH}_{2} \mathrm{CF}_{3}$ & 1030 \\
\hline HFC-365mfc & $\mathrm{CH}_{3} \mathrm{CH}_{2} \mathrm{CF}_{2} \mathrm{CH}_{3}$ & 794 \\
\hline
\end{tabular}

R134a is perhaps the most widespread among HFCs. It has been used, for example, as a substitute for R12 (CFC) at medium and high temperatures in refrigeration and as an alternative to sulfur hexafluoride in magnesium metallurgy. In the conversion of plants from R12 to R134a, however, with the same compressor power, R134a provides a slightly lower cooling capacity than that obtained using R12. Furthermore, $\mathrm{R} 134 \mathrm{a}$ is harmful if inhaled, it is not flammable at room temperature and atmospheric pressure but it can become combustible if mixed with pressurized air.

Table 5 summarizes the main aspects of synthetic fluids.

Table 5. Aspects of synthetic fluids

\begin{tabular}{cccc}
\hline $\begin{array}{c}\text { Type of } \\
\text { Fluid }\end{array}$ & Environmental Impact & $\begin{array}{c}\text { Safety } \\
\text { class }\end{array}$ & Performances \\
\hline CFC & High & A1 & High \\
\hline HCFC & High & A1/A2 & High \\
\hline HFC & Medium-High & A1/A2 & Good \\
\hline
\end{tabular}

\section{ENVIRONMENTAL COMPATIBILITY}

The compatibility of a refrigerant with the environment is described by three indexes:

- Ozone Depletion Potential (ODP) of a refrigerant fluid.

- Global Warming Potential (GWP): quantifies the direct greenhouse effect in terms of the amount of $\mathrm{kg}$ of carbon dioxide corresponding to one $\mathrm{kg}$ of refrigerant emitted into the atmosphere.

- Total Equivalent Warming Impact (TEWI) which considers the direct contribution to the greenhouse effect of a fluid and the indirect contribution due to the energy consumption necessary for the operation of the equipment, as follows:

$$
T E W I=\mathrm{CO}_{2, \text { dir }}+\mathrm{CO}_{2, \text { indir }}
$$

Over the years, the need to regulate and, in many cases, to limit the use of refrigerating fluids, which have been largely responsible for stratospheric ozone depletion and global warming, has increasingly felt stronger. The main legislative regulations introduced, in chronological order, are: the Montreal Protocol, the Kyoto Protocol from which the EU Regulation No. 2037/2000, the European Directive 842/2006 and the EU Regulation No. 517/2014 [21].

EU Regulation 2037/00 prohibits the production and use of CFCs from 1 January 2000. EU Regulation 2037/00 prohibits the production and use of HCFCs from 1 January 2015. The EU Regulation 517/14 establishes a progressive reduction of HFCs in all fields of application. From an environmental point of view, the regulations first dealt with the disposal of gases with high ODP values, and then concentrated on the gases that contribute to global warming according to the diagram shown in Figure 4: 


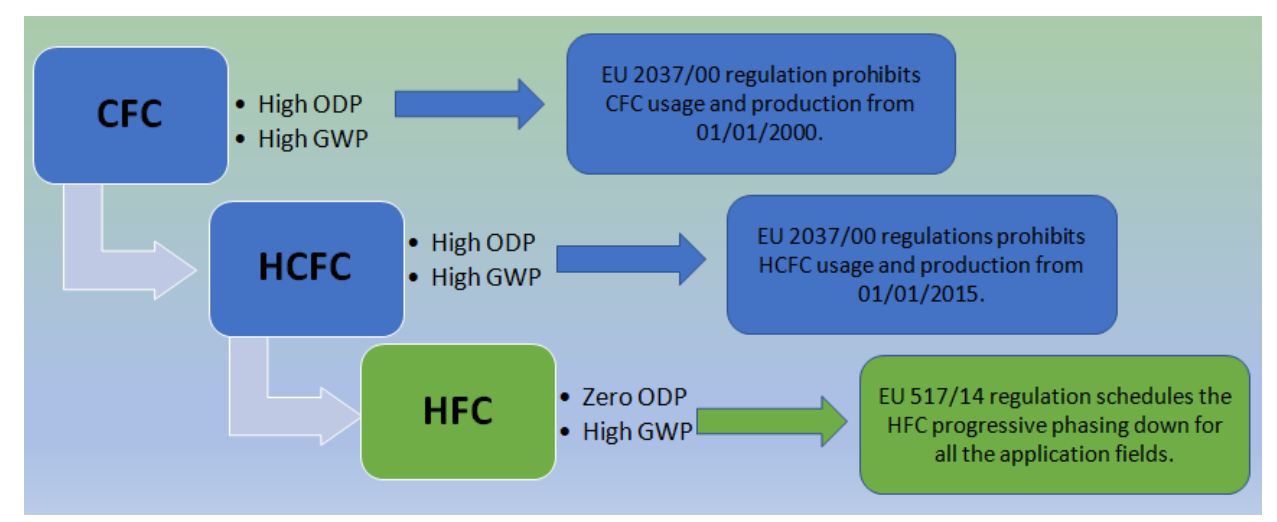

Figure 4. Evolution of refrigerant fluids based on the regulations introduced

Therefore, currently the problem of environmental compatibility still being resolved is linked to global warming. Regulations have therefore been issued, resulting from the Kyoto Protocol, aimed at reducing greenhouse gas emissions. At European level the indications contained in the Kyoto Protocol have resulted in the drafting and approval of the European regulation N 842 of 2006. On 1 January 2015, the European Regulation $\mathrm{N}^{\circ} 517 / 14$ replaced the previous regulation 842/06. This regulation introduces a series of innovations concerning the marketing, use, recovery and disposal of HFCs. The legislation establishes a timeline to be respected for the countries of the European Union regarding a progressive (phase-down) reduction of the F-gas quantities introduced on the European market compared to the quantity introduced in the three-year period 2009-2012. These quantities are expressed in tons of $\mathrm{CO}_{2 \mathrm{eq}}$ and do not depend on the type of refrigerant. The goal is to achieve a $79 \%$ reduction in emissions by 2030, as shown in Figure 5. Basing the emission count no longer on the quantities in $\mathrm{kg}$ of refrigerant but on the emissions in tons of carbon dioxide equivalent, the regulation emphasizes the importance of using fluids with low GWP. In this sense it also provides provisions on the banning of various refrigerant fluids in different fields of application, as shown in Table 6 .
Other provisions of the regulation concern the control of refrigerant leaks. The frequency of the controls does not depend on the amount of fluid used in the equipment but on the emissions in terms of tons of carbon dioxide. So, the controls will be more frequent the higher the GWP value of the refrigerant under examination. Furthermore, Directive $517 / 14$ imposes not only on operators in charge of maintenance/control, but also on companies that supply fluorinated greenhouse gases, the obligation to draw up a register (Article 6) containing: the number of certificates held by the buyers specifying in which category they fall: control, recovery, installation, maintenance and repair; the respective quantities of fluorinated greenhouse gases purchased. The recovery, regeneration, recycling or destruction of fluorinated greenhouse gases is described in Article 8 and applies to the following equipment:

- cooling circuits for stationary refrigeration, fixed air conditioning and fixed heat pumps;

- cooling circuits of refrigeration units of trucks and refrigerated trailers;

- fixed equipment containing solvents based on fluorinated greenhouse gases;

- fixed fire protection equipment;

- fixed electrical switches.



Figure 5. HFC Phase-down from 2015 to 2030 
Table 6. F-gas bans based on their GWP

\begin{tabular}{|c|c|c|}
\hline Application & Refrigerant & $\begin{array}{c}\text { Prohibition } \\
\text { begins }\end{array}$ \\
\hline Domestic refrigerators and freezers & $\begin{array}{l}\text { HFC with GWP } \geq \\
150\end{array}$ & $01 / 01 / 2015$ \\
\hline Refrigerators and freezers for commercial use & $\begin{array}{l}\text { HFC with GWP } \geq \\
2500\end{array}$ & $01 / 01 / 2020$ \\
\hline Refrigerators and freezers for commercial use (hermetically sealed equipment) & $\begin{array}{l}\text { HFC with GWP } \geq \\
150 \\
\end{array}$ & $01 / 01 / 2022$ \\
\hline $\begin{array}{l}\text { Fixed refrigerating and air conditioning equipment (with the exceptions of apparatus for } \\
\text { refrigerating below }-50^{\circ} \mathrm{C} \text { ) }\end{array}$ & $\begin{array}{l}\text { HFC with GWP } \geq \\
2500\end{array}$ & $01 / 01 / 2020$ \\
\hline Mobile air conditioning equipment for environments & $\begin{array}{l}\text { HFC with GWP } \geq \\
150\end{array}$ & $01 / 01 / 2020$ \\
\hline Monosplit air conditioning systems employing less than $3 \mathrm{~kg}$ of fluorinating greenhouse gases & $\begin{array}{l}\text { HFC with GWP } \geq \\
750\end{array}$ & $01 / 01 / 2025$ \\
\hline $\begin{array}{l}\text { Centralized multipack systems for commercial use and nominal capacity equal or greater than } \\
\qquad 40 \mathrm{~kW}\end{array}$ & $\begin{array}{l}\mathrm{HFC} \text { con GWP } \geq \\
150\end{array}$ & $01 / 01 / 2022$ \\
\hline
\end{tabular}

\section{REPLACEMENT FLUIDS}

The new regulation poses the problem of finding substitutes for all HFCs that do not respect the GWP limits. Based on the limits on the GWP values set by the legislation, in the short term (5-10 years) we will see the gradual replacement of high GWP refrigerants with lower GWP HFCs whereas, in the long term (10-20 years) they will be introduced on market nonclimate altering substances with very low or zero GWP. If in the short term new HFC fluids with a lower GWP are already available, in the long term the comparison between two categories is envisaged: last generation of synthetics fluids and natural ones.

The natural fluids on which the industries and research centers are concentrating are ammonia, carbon dioxide and hydrocarbons, mentioned in the previous paragraphs. Investments in this field are mainly focused on the development of technologies that make it possible to overcome those that have historically been the limits to diffusion in all sectors of these substances: efficiency in all conditions of use and safety.

The main substitutes for HFCs belonging to the category of the latest generation of synthetic fluids are the HFOs, HydroFluoro-Oleifins deriving from propane by partial substitution of the hydrogen atoms with fluorine. Being very reactive compounds, they have a very short life in the atmosphere. This results in very low GWP values which make them excellent candidates for HFC replacement in many sectors. They are not toxic while the flammability varies from fluid to fluid depending on the operating temperature. In terms of energy efficiency, HFOs seem to offer good guarantees but are still being tested.

The first hydrofluoroolefins to be marketed are HFO1234ze and HFO-1234yf. The latter became mandatory from 1 January 2017, according to directive 40/06, in air conditioning systems for cars instead of R134a. From the economic point of view these substances are more expensive than traditional HFCs, but it is believed that their cost is destined to decline over the next few years. They are designed to work both in existing systems, with no or some modifications, or in new systems. However, there is one aspect that could slow down the use of these compounds. Despite the low GWP values of these fluids, the process of decomposition of the HFOs once released into the atmosphere is still unclear. Like all fluorinated compounds, HFOs also decompose into hydrofluoric acid and trifluoroacetic acid (TFA). Unlike traditional HFCs that degrade in TFA only in a small percentage (from 7 to $20 \%$ ), the HFOs decompose completely in TFA. TFA contributes to rain acidification, is toxic if inhaled and harmful to aquatic organisms. Since trifluoroacetic is already present in nature, it is not yet clear whether the use of HFOs can alter concentrations in various ecosystems. However, it is considered necessary to further investigate this aspect before using these fluids massively. Table 7 shows the characteristics of some HFOs.

Table 7. HFO properties

\begin{tabular}{cccc}
\hline GWP & HFO1234yf & HFO1234ze & HFO1233zd \\
\hline Safety class & A2 & A2L & A1 \\
\hline $\begin{array}{c}\text { Thermodynamic } \\
\text { efficiency }\end{array}$ & High & under study & under study \\
\hline Possible uses & $\begin{array}{c}\text { HFC134a } \\
\text { replacement } \\
\text { in car air } \\
\text { conditioners } \\
\text { from } \\
01 / 01 / 2017\end{array}$ & $\begin{array}{c}\text { HFC134a } \\
\text { replacement } \\
\text { in industrial } \\
\text { chillers }\end{array}$ & $\begin{array}{c}\text { air } \\
\text { conditioning }\end{array}$ \\
\hline
\end{tabular}

Figure 6 shows new low-medium GWP mixtures [22-24].

\begin{tabular}{|c|c|c|c|c|c|}
\hline Name & Composition & $\mathrm{T}(\mathrm{K})$ Glide & $\begin{array}{l}\text { Safety } \\
\text { class }\end{array}$ & $\begin{array}{l}\text { Refrigerant to } \\
\text { be substitute }\end{array}$ & GWP \\
\hline R407G & $\begin{array}{c}\mathrm{R}-32 / 125 / 134 \mathrm{a} \\
(2.5 / 2.5 / 90)\end{array}$ & 2 & A1 & HFC134a & 1400 \\
\hline R449B & $\begin{array}{c}\text { R-32/125/1234yf/134a } \\
(25.2 / 24.3 / 23.2 / 27.3)\end{array}$ & 5.9 & A1 & $\begin{array}{l}\text { HCFC22 } \\
\text { HFC404A } \\
\text { HFC407C }\end{array}$ & 1300 \\
\hline R453A & $\begin{array}{c}\text { R-32/125/134a/227ea/ } \\
600 / 601 a \\
(20 / 20 / 53.8 / 5 / 0.6 / 0.6)\end{array}$ & 7.2 & A1 & $\begin{array}{l}\text { HCFC22 } \\
\text { HFC407C }\end{array}$ & 1700 \\
\hline R454A & R-1234yf/32 (65/35) & 6.8 & A2L & HFC404A & 250 \\
\hline R454B & $\begin{array}{l}\text { R-32/1234yf } \\
(68.9 / 31.1)\end{array}$ & 0.9 & A2L & HFC410A & 490 \\
\hline R455A & $\begin{array}{c}\text { R-744/32/1234yf } \\
(3 / 21.5 / 75.5)\end{array}$ & 12.5 & A2L & $\begin{array}{l}\text { R404A } \\
\text { R410A }\end{array}$ & 150 \\
\hline
\end{tabular}

Figure 6. Features of new low-medium GWP mixtures 


\section{CONCLUSIONS}

The main purpose of the present paper is to provide a detailed general framework of the state of the art related to the reduction of greenhouse gas emissions in refrigeration. It is therefore possible to reach the following conclusions:

- HFCs are a class of refrigerants that has dominated the refrigeration panorama as they are linked to various advantages such as high energy efficiency, safety, availability on the market and low costs. The main disadvantage shown by them was that which led to their progressive disposal, i.e. high GWP.

- There was an increase in HFC costs following the estimated phase-down in $+35 € / t$ of $\mathrm{CO}_{2}$, eq at 2030 .

- From 2022 all refrigerants with GWP above 150 will be banned.

- Among the main problems related to the aforementioned disposal there is the retro-fit of the existing plants.

- The main alternative to HFCs is made up of both pure HFOs (advantages: low GWP, non-toxic, drop-in. Disadvantages: high cost, efficiency, moderately flammable); or mixtures of HFCs and HFOs (advantages: low GWP, drop-in. Disadvantages: deterioration of heat exchange coefficients, lower energy efficiency, change of composition due to leaks).

\section{REFERENCES}

[1] Montreal Protocol on Substances that deplete the ozone layer. United Nation Environment Program (UN), New York (NY), USA, 1987.

[2] de Chazournes, L.B. (1997). Kyoto Protocol to the United Nation Framework Convention on Climate Change. United Nation Environment Program (UN), Kyoto, JPN.

[3] Heath, E.A. (2017). Amendment to the Montreal protocol on substances that deplete the ozone layer (Kigali Amendment). International Legal Materials, 56(1): 193-205. https://doi.org/10.1017/ilm.2016.2

[4] The European Parliament and the Council. (2014). No $517 / 2014$ of the European Parliament and of the Council of 16 April 2014 on fluorinated greenhouse gases and repealing Regulation (EC) No 842/2006 Text with EEA relevance. Off. J. Eur. Union L.

[5] Ciconkov, R. (2018). Refrigerants: There is still no vision for sustainable solutions. International Journal of Refrigeration, 86: 441-448. https://doi.org/10.1016/j.ijrefrig.2017.12.006

[6] Aprea, C., Greco, A., Maiorino, A., Masselli, C. (2018). The drop-in of HFC134a with HFO1234ze in a household refrigerator. International Journal of Thermal Sciences, 127:

117-125.

https://doi.org/10.1016/j.ijthermalsci.2018.01.026

[7] Aprea, C., Greco, A., Maiorino, A., Masselli, C., Metallo, A. (2016). HFO1234ze as drop-in replacement for R134a in domestic refrigerators: An environmental impact analysis. Energy Procedia, 101: 964-971. https://doi.org/10.1016/j.egypro.2016.11.122

[8] Aprea, C., Greco, A., Maiorino, A., Masselli, C., Metallo, A. (2016). HFO1234yf as a drop-in replacement for $\mathrm{R} 134 \mathrm{a}$ in domestic refrigerators: A life cycle climate performance analysis. International Journal of Heat and Technology, 34(2): S212-S218. https://doi.org/10.18280/ijht.34S204

[9] Navarro-Esbrí, J., Mendoza-Miranda, J.M., MotaBabiloni, A., Barragán-Cervera, A., Belman-Flores, J.M. (2013). Experimental analysis of R1234yf as a drop-in replacement for R134a in a vapor compression system. International Journal of Refrigeration, 36(3): 870-880. https://doi.org/10.1016/j.ijrefrig.2012.12.014

[10] Mota-Babiloni, A., Navarro-Esbrí, J., Barragán, Á., Molés, F., Peris, B. (2014). Drop-in energy performance evaluation of R1234yf and R1234ze (E) in a vapor compression system as R134a replacements. Applied Thermal Engineering, 71(1): 259-265. https://doi.org/10.1016/j.applthermaleng.2014.06.056

[11] Mota-Babiloni, A., Navarro-Esbrí, J., Molés, F., Cervera, Á.B., Peris, B., Verdú, G. (2016). A review of refrigerant R1234ze (E) recent investigations. Applied Thermal Engineering, 95: 211-222. https://doi.org/10.1016/j.applthermaleng.2015.09.055

[12] Molés, F., Navarro-Esbrí, J., Peris, B., Mota-Babiloni, A., Barragán-Cervera, Á. (2014). Theoretical energy performance evaluation of different single stage vapour compression refrigeration configurations using R1234yf and R1234ze (E) as working fluids. International Journal of Refrigeration, 44: 141-150. https://doi.org/10.1016/j.ijrefrig.2014.04.025

[13] Mota-Babiloni, A., Navarro-Esbrí, J., Barragán-Cervera, Á., Molés, F., Peris, B. (2015). Drop-in analysis of an internal heat exchanger in a vapour compression system using R1234ze (E) and R450A as alternatives for R134a. Energy, 90: 1636-1644. https://doi.org/10.1016/j.energy.2015.06.133

[14] Mohanraj, M., Jayaraj, S., Muraleedharan, C., Chandrasekar, P. (2009). Experimental investigation of R290/R600a mixture as an alternative to R134a in a domestic refrigerator. International Journal of Thermal Sciences, 48(5): 1036-1042. https://doi.org/10.1016/j.ijthermalsci.2008.08.001

[15] Lee, Y.S., Su, C.C. (2002). Experimental studies of isobutane (R600a) as the refrigerant in domestic refrigeration system. Applied Thermal Engineering, 22(5): 507-519. https://doi.org/10.1016/S13594311(01)00106-5

[16] Bansal, P., Vineyard, E., Abdelaziz, O. (2011). Advances in household appliances - A review. Appl. Therm. Eng., 31(17): 3748-3760. https://doi.org/10.1016/j.applthermaleng.2011.07.023

[17] Mohanraj, M., Jayaraj, S., Muraleedharan, C. (2009). Environment friendly alternatives to halogenated refrigerants-A review. International Journal of Greenhouse Gas Control, 3(1): 108-119. https://doi.org/10.1016/j.applthermaleng.2011.07.023

[18] Greco, A., Mastrullo, R., Palombo, A. (1997). R407C as an alternative to R22 in vapour compression plant: an experimental study. International Journal of Energy Research, 21(12): 1087-1098. https://doi.org/10.1002/(SICI)1099$114 X(19971010) 21: 12$

[19] Aprea, C., Greco, A. (1998). An experimental evaluation of the greenhouse effect in R22 substitution. Energy Conversion and Management, 39(9): 877-887. https://doi.org/10.1016/S0196-8904(97)10058-9

[20] Greco, A., Vanoli, G.P. (2005). Flow boiling heat 
transfer with HFC mixtures in a smooth horizontal tube. Part II: Assessment of predictive methods. Experimental Thermal and Fluid Science, 29(2): 199-208. https://doi.org/10.1016/j.expthermflusci.2004.03.004

[21] Höglund-Isaksson, L., Purohit, P., Amann, M., Bertok, I., Rafaj, P., Schöpp, W., Borken-Kleefeld, J. (2017). Cost estimates of the Kigali Amendment to phase-down hydrofluorocarbons. Environmental Science \& Policy, 75:

138-147.

https://doi.org/10.1016/j.envsci.2017.05.006

[22] Aprea, C., Greco, A., Maiorino, A. (2017). An experimental investigation of the energetic performances of HFO1234yf and its binary mixtures with HFC134a in a household refrigerator. International Journal of
Refrigeration, 76:

109-117.

https://doi.org/10.1016/j.ijrefrig.2017.02.005

[23] Mendoza-Miranda, J.M., Mota-Babiloni, A., NavarroEsbrí, J. (2016). Evaluation of R448A and R450A as low-GWP alternatives for R404A and R134a using a micro-fin tube evaporator model. Applied Thermal Engineering, 98:

330-339. https://doi.org/10.1016/j.applthermaleng.2015.12.064

[24] Makhnatch, P., Mota-Babiloni, A., Khodabandeh, R. (2017). Experimental study of R450A drop-in performance in an R134a small capacity refrigeration unit. International Journal of Refrigeration, 84: 26-35. https://doi.org/10.1016/j.ijrefrig.2017.08.010 